\title{
IMPOSIÇÕES E CONFLITOS NO COTIDIANO DAS FAMÍLIAS DE CRIANÇAS COM DOENÇA CRÔNICA
}

\author{
Impositions and conflicts on the daily routine of families of children with chronic disease \\ Imposiciones y conflictos en el cotidiano de las familias con niños con enfermedad \\ crónica
}

\author{
Vanessa Medeiros da Nóbrega ${ }^{1}$ \\ Simone Elizabeth Duarte Coutinho ${ }^{4}$
}

Altamira Pereira da Silva Reichert ${ }^{2}$

Kenya de Lima Silva ${ }^{3}$

Neusa Collet $^{5}$

\section{RESUMO}

Estudo descritivo-exploratório com abordagem qualitativa com o objetivo de identificar as imposições e os conflitos enfrentados no cotidiano pelas famílias de crianças com doença crônica. Os dados foram coletados entre novembro de 2008 e janeiro de 2009 mediante entrevistas semiestruturadas realizadas em um hospital público, referência no tratamento de doença crônica, com três famílias residentes no município de João Pessoa - PB, e processados a partir da análise temática. Os resultados apontam que os conflitos e imposições no cotidiano da família envolvem o abandono do emprego, ocasionando desequilíbrio financeiro; redução/ interrupção dos momentos de lazer; incompreensão social e familiar; sobrecarga do cuidador principal; desestruturação familiar e relacionamentos fragilizados com repercussão negativa em toda família. Aponta-se a necessidade de os profissionais de saúde conhecerem o contexto de vida da criança com doença crônica e sua família, a fim de obterem elementos para um planejamento adequado de superação dos percalços decorrentes da doença.

Palavras-chave: Doença crônica. Família. Enfermagem pediátrica. Criança.

\section{Abstract}

Descriptive-exploratory study with qualitative approach in order to identify the impositions and conflicts faced on the daily routine by the families of children with chronic disease. Data were collected between November/2008 and January/2009 through semistructured interviews conducted in a public hospital, reference for the treatment of chronic disease, with three families that live in the city of João Pessoa - PB, and processed through thematic analysis. The results show that the conflicts and impositions in the family routine include the abandonment of the job, resulting in financial problems; reduction/interruption of leisure moments; social and family misunderstanding; over demanding the main caretaker; loss of family structure and weakened relationships with negative repercussions for the whole family. It is emphasized that the health professionals need to know the life context of the children with chronic disease and their families in order to have elements for an appropriate planning to overcome the constraints that result from the disease.

Keywords: Chronic disease. Family. Pediatric nursing. Child.
Estudio descriptivo-exploratorio con aportación cualitativa con el fin de identificar las imposiciones y los conflictos enfrentados en el cotidiano por los familiares de niños con enfermedad crónica. Los datos fueron recogidos entre noviembre de 2008 y enero de 2009, por medio de entrevistas semi-estructuradas realizadas en un hospital público, referencia en el tratamiento de enfermedades crónicas, con tres familias que viven en el municipio de João Pessoa (PB), y procesados a partir del análisis temático. Los resultados apuntan que los conflictos e imposiciones en el cotidiano de la familia envuelven el abandono del empleo, provocando desequilibrio financiero; reducción/interrupción de los momentos de ocio; incomprensión social y familiar; sobrecarga del cuidador principal; desestructuración familiar y relaciones débiles con repercusión negativa en toda la familia. Se apunta la necesidad de los profesionales de salud en conocer el contexto de vida del niño con enfermedad crónica y su familia, con vistas a tener elementos para un planeamiento adecuado de superación de los obstáculos resultantes de la enfermedad.

Palabras clave: Enfermedad crónica. Familia. Enfermería pediátrica. Niño.

\footnotetext{
${ }^{1}$ Mestranda do Programa de Pós-Graduação em Enfermagem da Universidade Federal da Paraíba - UFPB. João Pessoa - PB. Brasil, e-mail: nessanobregam@hotmail.com.; 2 Enfermeira, Doutora em Saúde da Criança e do Adolescente, Docente do Curso de Graduação e Pós-Graduação em Enfermagem da Universidade Federal da Paraíba - UFPB. João Pessoa-PB. Brasil. E-mail: altareichert@gmail.com.; ${ }^{3}$ Doutoranda do Programa de Pós-Graduação em Enfermagem Fundamental da Escola de Enfermagem de Ribeirão Preto - Universidade de São Paulo. Docente do Curso de Graduação em Enfermagem da UFPB. Enfermeira Assistencial da Clínica Pediátrica do Hospital Universitário Lauro Wanderley/UFPB. João Pessoa - PB. Brasil. E-mail: kenya.cateq@gmail.com.; ${ }^{4}$ Enfermeira, Doutoranda do Programa de Pós-Graduação em Enfermagem da Universidade Federal da Paraíba, Docente do Curso de Graduação em Enfermagem da Universidade Federal da Paraíba- UFPB. João Pessoa- PB. Brasil. E-mail: simonedc_3@hotmail.com.; ${ }^{5}$ Enfermeira, Doutora em Enfermagem, Docente do Curso de Graduação e Pós-Graduação em Enfermagem da Universidade Federal da Paraíba - UFPB. João Pessoa - PB. Brasil. E-mail: neucollet@gmail.com.
} 


\section{INTRODUÇÃO}

0 curso da doença crônica percorre caminhos incertos e traz importantes repercussões na vida e na dinâmica das familias. Nesse sentido, a doença crônica na infância pode trazer um impacto significativo sobre o funcionamento familiar ${ }^{1}$, uma vez que afeta o desenvolvimento normal da criança e as relações sociais, com alterações que envolvem, desde a separação/divórcio dos pais, até a confusão de papéis ou rupturas na sua dinâmica, levando, muitas vezes, a perdas importantes nos laços familiares e sociais².

A instabilidade no estado de saúde da criança necessita, muitas vezes, de rápidas mudanças, gerando conflitos, visto que essa realidade impõe modificações bruscas e inesperadas ao cotidiano. A familia enfrenta novas exigências, mudanças constantes e readaptações diversas, desencadeando efeitos nos níveis financeiro, ocupacional, pessoal e sociaß ${ }^{3}$. Sabe-se que o modo como,

respondem aos problemas advindos da doença são construídos socioculturalmente e remetem a um mundo compartilhado por crenças, valores e costumes [...] é na vida cotidiana que as pessoas constroem, conjuntamente, ações direcionadas para lidar com a doença: ${ }^{4: 639}$.

Dependendo da resposta da família aos conflitos/ problemas, repercutirá positiva ou negativamente na qualidade de vida e no bem-estar. Portanto, conhecer e compreender a realidade vivenciada pela família é fundamental no processo de construção de alicerces mais sólidos para seu fortalecimento, em busca de superar os percalços existentes na vida das pessoas envolvidas no processo do adoecer da criança.

Diante do exposto, o objetivo deste trabalho foi analisar as imposições e os conflitos no cotidiano das famílias de criança com doença crônica.

\section{MÉTODO}

Delineou-se um estudo de caráter exploratóriodescritivo, com abordagem qualitativa, baseado no depoimento de famílias que vivenciam a experiência de ter um filho com doença crônica. Trata-se de um estudo acerca da família, em que, a partir da experiência individual da mãe, construiu-se 0 contexto descrito, representado pela sua percepção sobre a dinâmica e a vida familiar diante da doença crônica de seu filho. Considera-se a mãe um membro significativo para representar a família, por ela participar ativamente da construção e da organização do cotidiano no domićlio.

A pesquisa foi realizada em um hospital público do município de João Pessoa, Paraíba, no período de novembro de 2008 a janeiro de 2009. Os critérios de inclusão dos sujeitos da pesquisa foram: ser mãe/acompanhante de criança com doença crônica; estar com a criança hospitalizada na Clínica Pediátrica do hospital em estudo durante o período de produção do material empírico; ter uma criança com mais de um ano de diagnóstico de doença crônica; residir com a família no perímetro urbano de João Pessoa; ter mais de dezoito anos. Foram excluídas do estudo famílias residentes fora do perímetro urbano de João Pessoa e que tivessem problemas de comunicação.

Portanto, os sujeitos da pesquisa constituíram-se de três mães de crianças com doença crônica, cujo acesso se deu por intermédio de um levantamento realizado na clínica pediátrica de uma instituição pública do município de João Pessoa - Paraíba, referência no tratamento de criança com doença crônica no Estado da Paraíba. No levantamento dos possíveis participantes do estudo, foi constatado que mais de $90 \%$ das crianças com doenças crônicas hospitalizadas na clínica pediátrica residiam em outros municípios do interior da Paraíba.

A coleta de dados ocorreu por meio da entrevista semiestruturada, que permitiu ao pesquisador maior flexibilidade na organização do tempo, com ampla liberdade para fazer intervenções de acordo com 0 andamento da entrevista. A entrevista, por intermédio de uma conversa, ao mesmo tempo em que é um modo de interação social, tem a finalidade e o objetivo de construir informações relacionadas ao objeto de pesquisa ${ }^{5}$.

Todas as entrevistas foram gravadas, com anuência dos entrevistados, a fim de captar a fala dos sujeitos na íntegra. 0 roteiro da entrevista foi constituído por duas partes: a primeira, com dados referentes ao grau de parentesco da entrevistada, bem como a idade, o sexo, o tipo e o tempo de diagnóstico da doença crônica da criança; e a segunda, com a questão norteadora: "Fale-me sobre o cotidiano familiar diante da doença crônica de seu filho, desde o início dos primeiros sinais e sintomas da doença até os dias atuais".

As entrevistas tiveram duração média de 40 minutos e foram transcritas na íntegra, sendo os dados processados a partir dos princípios da análise temática de acordo com os seguintes passos: ordenação dos dados; classificação dos dados e análise final ${ }^{5}$. Desse modo, permitiu-se organizar e estruturar as partes, relacionando-as e identificando os núcleos de sentido. Em seguida, ocorreu o agrupamento dos dados e a extração da categoria empírica que constituiu a construção organizada dos dados empíricos: imposições e conflitos enfrentados pelas famílias de criança com doença crônica em seu cotidiano.

0 estudo foi norteado pelas diretrizes e pelas normas regulamentadoras de pesquisa, envolvendo seres humanos, preconizadas na Resolução No 196/96 do Conselho Nacional de Saúde 6 . A produção do material empírico iniciou-se após aprovação do projeto pelo Comitê de Ética em Pesquisa do hospital em estudo sob o protocolo $n^{0}$ 090/08. Todos os participantes assinaram o Termo de Consentimento Livre e Esclarecido.

Como garantia do anonimato dos participantes deste estudo, as mães e as crianças com doença crônica 
foram identificadas por letras (M para mãe e C para criança) acompanhadas de números ordinais nos resultados e discussão (M1-C1, M2-C2 e M3-C3), de acordo com a ordem de realização das entre

\section{RESULTADOS E DISCUSSÃO}

Dentre as famílias que participaram do estudo, duas eram constituídas por pai, mãe e filho(s), em que a figura paterna era representada pelo padrasto, e uma composta pela mãe e seus filhos. As crianças eram do sexo masculino com as seguintes idades, doenças crônicas e tempo de diagnóstico: $\mathrm{C1}$ onze anos, Anemia Falciforme e seis anos de diagnóstico; C2 oito anos, Leucemia Linfoide Aguda e um ano de diagnóstico; e C3 sete anos acometido por Feocromocitoma, tumor no pâncreas, com cinco anos de diagnóstico.

Os dados revelaram que a doença crônica na infância ocasionou profundas transformações na dinâmica e na vida familiar, devido às necessidades intrínsecas desencadeadas pela doença na família, levando a um processo de desestruturação e de modificação dos papéis desempenhados por cada membro, resultando em momentos conflituosos e na interferência no cotidiano.

Esse aspecto é corroborado em um pesquisa ${ }^{1}$ que destaca que a doença crônica ou deficiência em uma criança pode suscitar sobrecarga física, de tempo, financeira e psicológica à família. Essa sobrecarga pode causar risco adicional substancial para desencadear disfunções, assim como resultados adversos na saúde da criança e de seus familiares.

Deparando-se com essa realidade, a reorganização dos papéis diante das necessidades de cuidado traz significativas repercussões para a dinâmica e a vida das pessoas que convivem com uma criança com doença crônica. Uma das primeiras mudanças ocorridas é 0 abandono do emprego de um dos pais para acompanhar o filho durante a hospitalização ou em consultas frequentes e na realização de exames. Geralmente, a mãe é a responsável por esse papel ${ }^{7}$.

Antes de receber esse benefício, eu passei muita dificuldade com meus filhos porque eu trabalhava, mas eu deixei de trabalhar por causa de C3 [...] Tinha dia que eu não tinha nada para dar para o meu filho [...] Foi um momento muito difícil [...] (M3).

Observa-se, no fragmento discursivo, uma realidade comumente vivenciada pelas famílias ao necessitar manter a criança com doença crônica em tratamento: 0 abandono do emprego. Esta realidade foi enfatizada em vários estudos ${ }^{1-2,8}$ devido à necessidade de cuidar da criança em tempo integral, em razão das incertezas do curso da doença, com desequilíbrio nas finanças, que afeta a qualidade de vida de todos.
0 desequilíbrio financeiro, em decorrência dos gastos e das imposições da doença crônica, pode ocasionar redução ou até interrupção dos momentos de lazer necessários para restaurar as energias e fortalecer as famílias, dificultando a superação dos percalços oriundos da caminhada, deixando-as mais vulneráveis psicologicamente.

A gente quase não sai. É que eu nunca tenho dinheiro suficiente para estar gastando com eles. [...] 0 dinheiro é muito pouco para muita coisa, muita coisa, não dá. [...] Eu nunca saio com eles, é muito difícil, muito difícil mesmo. [...] (M3).

A repetição dos advérbios de intensidade muito e muita, inconscientemente, evidencia o não dito referente à sobrecarga oriunda das necessidades da doença crônica como muitos gastos, muitas demandas familiares, incluindo o desgaste emocional, o que torna tudo "muito" difícil, repercutindo desfavoravelmente nos momentos de lazer, que se tornam raros.

Eu queria trabalhar pagar as contas e dar o melhor para o meu filho, mas não posso por causa dele. Hoje ele está assim bom, mas amanhã... (M3).

Percebe-se uma adversidade nos sentimentos que gera conflito interno "eu queria trabalhar" " "mas não posso", pois a mãe quer trabalhar para suprir as necessidades de seus filhos (lazer, alimentação, vestuário etc.) e, ao mesmo tempo, deseja cuidar da criança com doença crônica. No fragmento discursivo "Hoje ele está assim bom, mas amanhã....", nota-se, pela interrupção no discurso, a dificuldade da mãe em falar de futuro para o filho, devido à insegurança por não saber os caminhos que a doença poderá seguir e o temor diante da possibilidade de piora do quadro clínico ou da perda da criança devido à doença.

Em outra realidade, M1 não abandonou o trabalho, mas relata os conflitos vivenciados quando há exacerbação dos sintomas da doença e a necessidade de hospitalização da criança.

[...] Da última vez eu faltei 3 dias. Eu ligo para o gerente ai falo com ele, ai ele (o gerente da loja onde trabalha) compreende a situação, mas fica meio assim né? [...] eu só falto quando ele (a criança) está internado. Às vezes eu estou assim doente, mas vou trabalhar assim mesmo [...] não gostam quando faltam a gente mesmo [...] eu faço o impossível para não faltar, para não chegar atrasada. Quando ele adoece, eu pago uma pessoa para ficar com ele. Eu só falto mesmo quando ele está mal [...] (M1).

No discurso de M1, observa-se a repetição da frase "eu só falto quando ele está (mal ou hospitalizado)" como se 
houvesse a necessidade de explicação por não ir ao trabalho e de aprovação de quem a escuta, pela atitude adotada para cuidar do filho. Enfatiza-se, também, a percepção de M1 diante da situação de hospitalização da criança, quando comunica o ocorrido para seus superiores, "ele (o gerente da loja onde trabalha) compreende a situação, mas fica meio assim, né?". 0 não dito no discurso de $\mathrm{M} 1$ revela que seu conflito diante desta situação é permeado por dúvidas: o comportamento do gerente para com minha situação está correto? Será que estou exagerando nas faltas? Será que posso perder o emprego? Uma maneira que M1 encontrou de não se ausentar demasiadamente no emprego foi contratar uma pessoa para ocupar o papel de cuidador, o qual vê como sua responsabilidade, no período em que ela está trabalhando: "eu pago uma pessoa para ficar com ele. Eu só falto mesmo quando ele está mal”.

Além disso, M1 deixa suas necessidades de saúde relegadas, na tentativa de compensar suas ausências no emprego: "Às vezes eu estou assim doente, mas vou trabalhar assim mesmo". Também se observa seu empenho para suprir as faltas com a assiduidade e a pontualidade nos dias em que pode ir trabalhar: "assim eu faço o impossivel para não faltar, para não chegar atrasada". Na expressão "o impossível", a palavra não dita revela a sobrecarga desgastante de M1 em relação aos múltiplos papéis assumidos pelas mulheres na atualidade, resultado da necessidade de a mulher ter uma nova identidade, além dos papéis cultural e socialmente determinados.

No estudo realizado sobre os múltiplos papéis sociais de mulheres cuidadoras/leigas de crianças hospitalizadas² , essa realidade foi constatada, evidenciando que as entrevistadas se consideraram como única executora do cuidado à criança em diferentes âmbitos (familiar, domiciliar, hospitalar, comunitário, entre outros). Percebe-se que a questão de gênero é intrínseca à sociedade, tendo fortes influências culturais perante os modos como as mães organizam sua vida e a dinâmica familiar diante das demandas desencadeadas pela doença crônica.

[...] Ontem mesmo eu estava fazendo uma faxina no meu quarto, na casa toda, pois eu trabalho a semana toda [...] ele (padrasto da criança) fica aí sem coragem [...] quando eu reclamo com ele [...] ele vai e faz [...] Para fazer uma coisa aqui é difícil. Não sei se isso é próprio dos homens (M1).

0 homem não percebe a sua responsabilidade com os afazeres domésticos e, somente quando a mulher demonstra insatisfação diante da situação, o companheiro começa a ajudar. Porém, mesmo assim, essa ajuda ainda é insuficiente diante das necessidades de apoio da mulher, como se percebe no fragmento "Para fazer uma coisa aqui é difíil".

M1 expressa estar ciente da mudança ocorrida no mundo contemporâneo em relação ao papel do homem, como se almejasse que essa atitude fosse interiorizada por seu companheiro.
Hoje em dia sei que tem muitos casos (de homens) que chegam em casa e o homem divide as tarefas com a mulher (M1).

Percebe-se a dificuldade que as mulheres ainda têm para dialogar com seu companheiro sobre a necessidade da divisão de tarefas domésticas diante da atual conjuntura familiar. A família nuclear está cada dia menor e mais isolada dos demais familiares, suscitando imensa responsabilidade para o núcleo familiar quando um de seus membros adoece. Caso não ocorra divisão de papéis apropriada, sobrecarrega uma pessoa e a possibilidade de conflitos e de desgaste no relacionamento do casal, bem como com os demais filhos, poderá ser maior.

A mulher geralmente exclui o homem do cuidado da criança hospitalizada e, com esse comportamento, associado à longa permanência afastada do lar, favorece a ruptura dos laços familiares entre o casal e demais integrantes da família².

0 homem, por ser excluído da participação dos cuidados à criança durante a hospitalização, não conhece a realidade vivenciada em decorrência da doença e, portanto, não compreende o afastamento da esposa ou da companheira do lar. Perante esse fato, começam a surgir desavenças entre o casal quando a criança inicia os sinais e os sintomas da doença e necessita de constantes hospitalizações.

[...] ele brigava logo quando o menino adoeceu. Quando a gente descobriu ele dizia que o menino estava internado porque eu queria [...] Porque eu não ia visitar ele, porque raramente eu deixava o menino só no hospital para ir estar com ele, porque não é justo isso. [...] Foi nessa época que eu me separei do meu marido. Ele tinha outra, sabendo da situação que eu estava (M3).

Nesse sentido, pode-se salientar que a magnitude da dedicação da mãe para com seu filho pode prejudicar a vida conjugal, pois ela deixa seu emprego, seu lar e suas tarefas domésticas, ficando voltada apenas para a criança que agora está doente e necessita de mais cuidados e atenção do que antes, negligenciando os outros membros da família ${ }^{9-10}$.

A literatura aponta que, geralmente, as famílias respondem bem a essa nova contingência. Contudo, podem ser observadas atitudes não cooperativas nas famílias em que os relacionamentos já estavam desgastados antes do estabelecimento da condição crônica. Apreende-se, então, que 0 adoecimento pode instigar ainda mais as dificuldades relacionais que estavam sendo fracamente contornadas 8 .

No caso dos participantes deste estudo, foi identificado que duas famílias eram constituídas por novas uniões e, por isso, quem ocupava a figura paterna era o padrasto. A mãe de C2, portador de Leucemia Linfocítica Aguda, relatou a convivência do casal: 
É regular, pois às vezes brigamos, mas depois se resolve. Minha briga mais com ele é porque ele não dá muita atenção a C2. Ele fala e tudo em casa, mas atenção como pai ele não dá. Dá muita atenção só para os dois menores, que ele é o pai, e minha arenga mais é por causa disso. Deixa o mais velho escanteado (M2).

As discórdias eram decorrentes da percepção da mãe de que o padrasto não assumiu o papel de pai. Observa-se nos fragmentos "ele não dá muita atenção a C2" e "atenção como pai ele não dá" a necessidade da mãe de que o marido se sinta responsável e avoque seu lado paterno, pois este trata a criança com doença crônica com indiferença, sem demonstrar afetividade.

Outra repercussão nos membros da família é encontrada no relacionamento da mãe com os demais filhos, pois há redução significativa da atenção, como consequência da preocupação e do foco da mãe centrado no cuidado à criança com doença crônica.

[...] Hoje deixei ele (a criança com doença crônica) aqui (no hospital) e fui em casa pegar roupa e olhar os outros meninos. [...] Quem fica em casa é o (irmão) mais velho que fica cuidando do mais novo, cozinha. (M3).

Observa-se, no fragmento em destaque, a transferência de responsabilidade do papel anteriormente materno para o filho adolescente. Esta situação acabou gerando conflitos entre o irmão mais velho e C3.

Brigam muito [...] 0 mais velho briga mais com C3. Dificilmente eles se unem. Mais fácil estar brigando (M3).

As desavenças podem estar relacionadas às mudanças ocasionadas na vida do adolescente com o agravo de saúde de C3, pelas quais o irmão saudável sente-se privado de vivenciar experiências próprias da sua idade. A agressividade e o vínculo conflituoso com a criança doente explicitaria, desse modo, a não aceitação da situação. A literatura ${ }^{11}$ revela um caso semelhante, porém de maneira mais explícita, por meio do estabelecimento de diálogos agressivos entre os irmãos saudáveis e a criança com doença crônica, em que o saudável culpa o irmão doente pelas circunstâncias difíceis que a família enfrentava.

0 estresse emocional crônico em família pode contribuir para o aparecimento de problemas psiquiátricos nos irmãos, especialmente nos meninos, que sofreram influências negativas na fase de estruturação da personalidade. Alteração problemática no comportamento e conduta mais agressiva podem estar relacionadas ao desequilíbrio da dinâmica familiar após o nascimento de um irmão deficiente e/ou da necessidade de rápido e forçado avanço no desenvolvimento para superar a necessidade de dependência ${ }^{12}$.

A mãe, além do sofrimento vivenciado com a doença crônica de C3, teve que enfrentar também o problema de outro filho com as drogas. Apesar disso, ela permanece desenvolvendo seu papel e não cogita a possibilidade em abandoná-lo, mesmo diante da desaprovação social.

\section{[...] dizem assim, como eu estou com esse problema desse meu filho, "é porque ele quer mulher, você não pode fazer nada, não'. Eu digo: 'posso porque eu sou mãe do meu filho. Ele pode ser o que for: um menino drogado, um ladrão, um marginal, mas é meu filho' [...] (M3).}

0 amor maternal construído ao longo do tempo, a formação de vínculos e a consolidação de laços afetivos a fez adotar uma postura na qual não impôs condições ao filho para continuar a seu lado. Ao contrário, esse amor incondicional a impediu de abandonar e renegar o filho, mesmo diante da desaprovação da comunidade, pois sabe que esta atitude traria prejuízos ainda maiores para a vida do adolescente. No momento que ele mais necessitou de apoio e compreensão, a mãe estava disposta a ajudá-lo e acreditava, ou pelo menos desejava, ser uma fase passageira.

A experiência vivenciada pela mãe, tanto em razão da doença crônica de C3 quanto pela drogadição do filho adolescente, surge como estressor capaz de suscitar sentimentos, como desesperança e fracasso. No entanto, mesmo sozinha para lidar com estas situações, ela desenvolve resiliência diante dos obstáculos.

0 adolescente convive em uma família monoparental, de baixa renda. De acordo com um estudo acerca da família e do uso de tabaco, de álcool e de drogas em adolescentes, que analisou dados referentes à Pesquisa Nacional de Saúde do Escolar, este perfil familiar possui uma vulnerabilidade social maior para a drogadição, como também ocorre uma sobrecarga de papéis para a manutenção das funções familiares ${ }^{13}$. Nesse mesmo estudo, foi identificado que a presença e a supervisão dos pais previnem comportamentos considerados prejudiciais aos jovens, reforçando a relevância que os laços familiares bem estruturados têm na vida dos adolescentes e na prevenção da drogadição.

A atenção integral às necessidades da criança com doença crônica fez com que a mãe dispensasse grande parte do seu tempo ao filho doente, impossibilitando-a de cuidar dos outros filhos como gostaria. As mulheres, nesta condição, ficam inquietas e verbalizam constantemente suas preocupações com os demais indivíduos da família, ao se encontrarem distantes de seus lares e sem contato com os outros integrantes. Para superar esta situação, outra mãe deste 
estudo buscou apoio familiar, obtendo colaboração nos cuidados com os irmãos na ausência da mãe:

[...] Minha mãe me apoia, gosta de mim, me ajuda ficando com as crianças. [...]. Com a minha mãe não posso falar, [...] ela não me entende (M2).

Estes dados revelam que a família extensa apoia o núcleo familiar, cuidando dos outros filhos para a mãe poder acompanhar a criança com doença crônica em suas necessidades. No entanto, o apoio emocional aparece fragilizado, devido à falta de espaços para uma relação dialógica e compreensiva com a família, sobrecarregando emocionalmente 0 sistema familiar, podendo deixá-lo mais fragilizado e exposto às demandas externas adversas.

A tendência do suporte familiar é diminuir com o tempo, pois os membros da família extensa não conseguem alterar o seu estilo de vida por muito tempo e, desse modo, não suprem a necessidade de apoio do núcleo ${ }^{8}$.

Minha família não me ajuda. [...] Eu passei nove meses aqui, nunca vieram dormir com C3 [...] Eu só tenho uma irmã que era para dar apoio dizer 'não, vai em casa que eu fico aqui'. Ela fica com o pequeno em casa, de vez em quando, e olha lá [...] (M3).

Durante o período de hospitalização, a mulher é a escolhida para o papel de acompanhante e, na maioria das famílias, não há revezamento de cuidadores, ficando a mulher afastada de seu lar, o que resulta em uma desorganização familiar ${ }^{8}$ Quando há uma criança hospitalizada, a mãe é a detentora quase unânime do papel de acompanhante. Este papel é, muitas vezes, imposto ou considerado inato, uma vez que ela, anteriormente ao estabelecimento da doença, o cumpria9.

Quanto há necessidade de hospitalização, os sentimentos de preocupação e de insegurança da criança em relação ao seu estado clínico vêm à tona e a mãe tenta aliviar esses sentimentos, fornecendo apoio emocional e estando junto com seu filho.

Ele, quando vem para o hospital, sabe que vai fazer os exames. Aí ele já fica, "mãe e se meus exames derem alto?", aí eu falo "isso é besteira não ligue não", [...] quando chegam os resultados, ele se interna. Ele fica triste, chora no primeiro dia, pede para ir embora [...] (M3).

$\mathrm{Na}$ hospitalização, a criança vivencia sentimentos relacionados ao medo do desconhecido, o qual correlaciona com o sofrimento físico, em decorrência dos procedimentos. Isso, por conseguinte, ocasiona sofrimento psicológico na criança ${ }^{9}$.
Outro achado, como consequência das constantes hospitalizações, consultas médicas e responsabilidade com os horários dos medicamentos, foi o impacto da doença crônica na vida social?:

Tem dia (semana) que a gente vai quatro vezes, porque na segunda, que ele faz exame de sangue, aí vai de manhã e vai de tarde. De tarde é como médico. Aívai na segunda [...], na terça e na quarta. Às vezes na quinta também. (M2)

[...] eu não vivo saindo, eu não vivo em festa, eu não vivo em canto nenhum. Eu sou de casa para casa, para vim para aqui (para o hospital), pronto. Aíeu viajo com C3 para São Paulo (para dar continuidade ao tratamento), volto [...] devido às muitas viagens, ele não aproveitou muita coisa (na escola) aí vai repetir (de ano escolar) porque não aprendeu nada. Ficou mais internado do que no colégio. No colégio ele é turista, só vai alguns dias e outros não, porque quando a gente viajou passou 2 meses em São Paulo, aífalta 15 dias. Quando vem, volta para aqui (para o hospital). Ele não sabe ler nem escrever [...] (M3).

0 impacto na vida das famílias, decorrente das demandas da criança doente, influencia na construção de laços sociais. A necessidade de afastamento prolongado do ambiente social pode interferir no processo de escolarização e na relação interpessoal da criança ${ }^{14}$. Uma das consequências sociais, também encontrada após o diagnóstico da doença crônica na criança, foi a redução do círculo de amizades:

Ele tinha dois amiguinhos, mas quando descobriram que ele estava com essa doença (LLA) se afastaram. Ele só tem o meu apoio em casa e de um priminho [...] É o único amigo que ele tem (M2).

A criança teve sua rotina modificada e dificultada pela condição crônica. A promoção da socialização das crianças com doenças crônicas é importante para maximizar as oportunidades de experimentar relacionamentos sociais positivos, pois as amizades se constituem em fator de proteção para as crianças e 0 apoio dos pais não compensa a rejeição e 0 afastamento dos amigos $^{15}$. Os pais devem apoiar e incentivar os filhos a estabelecer novas amizades, tendo em vista que elas favorecem a estimulação de independência dos filhos ${ }^{10}$.

Outro aspecto que se revela no discurso de M1 é a superproteção materna:

Os amiguinhos da escola são aqueles meninos bem rebeldes que só pensam em bater. Por isso eu estou lutando para ver se consigo um auxílio doença para colocar ele numa escolinha particular, para ver se 
consigo colocá-lo numa escolinha melhor para ele, porque onde ele está estudando... Aí tem muito daqueles meninos que gostam de arengar. [...] Ele era louco para andar de bicicleta, aí o pai (padrasto) deu uma. Eu deigraças a Deus quando o pneu furou. [...] 0 médico disse que não é bom para ele fazer muito esforço, aí achei ótimo ela ter furado o pneu [...] (M1).

Toda criança doente necessita de cuidados para que possa se recuperar mais rapidamente, como também existem doenças que necessitam de maiores cuidados, a exemplo das leucemias, pelo risco de surgimento de hematomas e de hemorragias. Entretanto, isso não justifica a superproteção materna, pois esse comportamento pode causar problemas no desenvolvimento da criança.

As famílias com esse comportamento e envolvimento excessivo com a criança podem desencorajar o desenvolvimento de suas potencialidades, traduzindo-se em uma maior dependência. 0 ato de superproteger a criança pode, também, provocar diminuição da autoestima, e, como consequência, ela pode se sentir "diferente" e incapaz, fortalecendo sua exclusão social ${ }^{16: 799}$.

A mãe utiliza-se da orientação médica "O médico disse que não é bom para ele fazer muito esforço" para justificar a superproteção, interpretando-a erroneamente, pois, na anemia falciforme, é contraindicado o esforço físico acentuado e o aumento da ingestão de líquidos durante a prática de atividades para evitar as crises falcêmicas. A família, caso não seja bem amparada e informada, pode não compreender as reais necessidades de saúde da criança doente e adotar uma atitude de distanciamento ou de superproteção ${ }^{14}$.

Além dos conflitos impostos pelo cotidiano, a família teve que aprender a lidar com as incer tezas da doença crônica e o medo constante da perda do filho.

Você está vendo, está lutando por seu filho, não sabe que dia ele vai. Não sabe se é manhã, depois, daqui a um mês, daqui a um ano, ninguém sabe. Mas dentro de você, você tem certeza [...] uma criança que desde os 8 meses vem lutando com isso, e quando veio descobrir foi quase 2 anos depois. Será que se tivessem descoberto quando ele tinha 1 ano, 9 meses será que já tinham curado ele [...]. Eu sei que um dia meu filho vai (M3).

A mãe demonstra atitude de luto antecipado ao ver o tempo passando e seu filho não apresentando melhora, pois, a partir do diagnóstico da doença crônica, a família passa a conviver mais de perto com a possibilidade de morte, porque reconhece um caminho para a consumação do fato. Mesmo sabendo se tratar de uma doença crônica, a mãe ainda associa a cronicidade da doença à demora do diagnóstico da criança.
Eu peço a Deus me preparar para no dia em que Ele levar numa hora em que eu esteja com paz no coração [...] (M3).

Percebe-se que a mãe recorreu ao espiritual, na tentativa de reduzir o desgaste psicológico e conseguir a resiliência necessária para superar os sentimentos originados a partir do pensamento da possibilidade de morte da criança. A literatura afirma que "a religião surge como elemento que permeia a experiência de doença da pessoa e da família, tornando-se um importante recurso de enfrentamento ${ }^{4: 643 "}$ ".

A morte e o luto são temas que as famílias não gostam de abordar, porém, diante da inquietação e da dúvida que a doença crônica da criança suscita, percebem ser possível a concretização da morte e isto assusta e desequilibra a vida. Nessa circunstância, a espiritualidade e a religiosidade surgem como formas de amenizar este medo e fazem com que a família encontre forças para enfrentá-lo e aceite o inevitável, possibilitando-a dar continuidade à vida cotidiana, cuidando da criança doente.

\section{CONSIDERAÇÕES FINAIS}

A família pode vivenciar diversos conflitos após o diagnóstico da doença crônica, dentre eles o abandono do emprego, gerando desequilíbrio financeiro, com consequente redução ou até interrupção dos momentos de lazer, incompreensão social e familiar, sobrecarga do cuidador principal, desestruturação familiar e relacionamentos fragilizados. Estes conflitos, tanto impostos pela condição crônica da criança quanto relacionados com a vida diária, deverão ser trabalhados para evitar o desequilíbrio do sistema familiar. Há necessidade de um planejamento de assistência focado na inclusão e na participação da família no processo do adoecer, em que todos se sintam copartícipes e compreendam as necessidades que envolvem a doença, contribuindo, assim, para o equilíbrio familiar.

Cada família é única e singular, por isso há necessidade de uma relação dialógica e empática entre profissionais de saúde e família para se conhecer o contexto no qual estão inseridos os envolvidos com a condição crônica na infância. Além disso, é importante apreender as necessidades de intervenção e/ou apoio da família para a superação dos conflitos que possam vir a acarretar graves consequências para a saúde dos envolvidos na condição crônica.

Ressalta-se que o enfrentamento das adversidades oriundas no percurso da doença crônica, quando trabalhados de modo apropriado, influencia positivamente na adaptação e, consequentemente, na resposta da família e da criança ao tratamento, resultando em melhor qualidade de vida.

Vale salientar as limitações do estudo, pois, apesar de abranger as vivências das famílias, esta não é uma realidade absoluta para todas que estão convivendo com a condição crônica na infância. A imprevisibilidade do curso da doença 
crônica poderá trazer outras imposições e conflitos que deverão ser considerados e avaliados pelos profissionais de saúde ao assistir a criança e sua família no direcionamento das ações para o alcance do sucesso terapêutico almejado. Nesse sentido, espera-se ter contribuído para a reflexão dos profissionais de saúde e, assim, para o surgimento de uma nova maneira de olhar e de pensar a assistência a esta clientela.

\section{REFERÊNCIAS}

1 Witt WP, DeLeire T. A Family perspective on population health: the case of child health and the family. WMJ. 2009 Aug; 108(5): 240-45.

2 Wegner W, Pedro ENR. Os múltiplos papéis sociais de mulheres cuidadoras-leigas de crianças hospitalizadas. Rev Gaucha Enferm. 2010 jun; 31(2): 335-42.

3 Gondim KM, Carvalho ZMF. Sentimentos das mães de crianças com paralisia cerebral à luz da teoria de Mishel. Esc Anna Nery. 2012 jan/mar; 16(1): 11-6.

4 Pizzignacco TP, Mello DF, Lima RG. A experiência da doença na fibrose cística: caminhos para o cuidado integral. Rev Esc Enferm USP. 2011 set; 45(3): 638-44

5 Minayo, MCS. 0 desafio do conhecimento: pesquisa qualitativa em saúde. 10ª ed. São Paulo: Hucitec; 2007. 408 p.

6 Conselho Nacional de Saúde (BR). Resolução nº 196, de 10 de outubro de 1996. Aprova as diretrizes e normas reguladoras de pesquisas envolvendo seres humanos. Diário Oficial da Republica Federativa do Brasil, Brasilia, DF, n. 201, 16 out 1996: Seção 1:21082

7 Steffen BC, Castoldi L. Sobrevivendo à tempestade: a influência do tratamento oncológico de um filho na dinâmica conjugal. Psicol Cienc Prof. 2006 set; 26(3): 406-25.

8 Montefusco SAR, Bachion MM. Manutenção do lar prejudicada: diagnóstico de enfermagem em familiares de pacientes hospitalizados com doenças crônicas. Rev Eletr Enferm. [on-line]. 2011 abr/jun; [citado 2012 jan 24]; 13(2): 182-89. Disponível em: http://www.fen.ufg.br/revista/ v13/n2/v13n2a04.htm.

9 Rossato LM, Angelo M, Silva CAA. Cuidando para a criança crescer apesar da dor: a experiência da família. Rev Latino-Am Enfermagem. 2007 jul/ago; 15(4): 556-62.

10 Viana V, Barbosa MC, Guimarães J. Doença crónica na criança: factores familiares e qualidade de vida. Psicol Saude Doenças. 2007 nov; 8(1): 117-27.

11 Paula ES, Nascimento LC, Rocha SMM. A influência do apoio social para o fortalecimento de famílias com crianças com insuficiência renal crônica. Rev Latino-Am Enfermagem. 2008 jul/ago; 16(4): 692-99.
12 Balottin U, Termine C, Quadrelli M, Brondolo S, Baratelli S, Zambonin F. Les frères des enfants atteints d'une maladie neurologique chronique: difficultés et besoins émotionnels. Psychiatrie de L'enfant. 2006 fev; 32 (1): 60-6.

13 Malta DC, Porto DL, Melo FCM, Monteiro RA, Sardinha LMV, Lessa BH. Família e proteção ao uso de tabaco, álcool e drogas em adolescentes, Pesquisa Nacional de Saúde dos Escolares. Rev Bras Epidemiol. 2011 fev; 14(1 supl): 166-77.

14 Pinho SR, Souza BSF, Cunha CCC, Costa DM, Nunes LN, Fonseca LCG, et al. Alterações comportamentais em crianças portadoras de enfermidades crônicas e suas repercussões na família: Hospital da Criança - Obras Sociais de irmã Dulce, Salvador( BA). Rev Cienc Med Biol. 2007 jan/abr; 6(1): 07-16.

15 Herzer M, Umfress K, Aljadeff G, Ghai K, Zakowski SG. Interactions with parents and friends among chronically ill children: examining social networks. J Dev Behav Pediatr. 2009 Dec; 30(6): 499-508.

16 Gilbert MJ, Mello DF, Lima RAG. Experiências de mães de filhos com Doença de Hirschsprung: subsídios para o cuidado de enfermagem. Esc Anna Nery. 2009 out/dez; 13(4): 793-801. 